\title{
Vascular thromboses with retroperitoneal fibrosis: a case report
}

\author{
Hanane Charaf ${ }^{1 *}$, Rachida Zahraoui ${ }^{1}$, Mouna Soualhi ${ }^{1}$, Nezha Rguig ${ }^{1}$, Jamal Eddine Bourkadi ${ }^{1}$, \\ Daoud Ali Mohamed ${ }^{2}$ and Nasser Ittimad ${ }^{2}$
}

\begin{abstract}
Background: Granulomatosis with polyangiitis is a systemic inflammatory disease characterized by necrotizing vasculitis that affects small- and medium-sized blood vessels. Granulomatous inflammation affects the lungs, ears, nose, and throat, and commonly affects the kidneys, although the retroperitoneal tissue is rarely affected. Several studies have reported an increased risk of venous thromboembolism. Early diagnosis and treatment are of vital importance due to the rapid progression of the disease.

Case presentation: We present the case of a 66-year-old Moroccan man followed for bilateral jugular thrombosis. Cavitary pulmonary nodules and retroperitoneal fibrosis with thrombosis involving several vascular territories were detected on thoracoabdominopelvic computerized tomography scan. Laboratory analyses revealed that the patient was positive for cytoplasmic antineutrophilic antibodies. The diagnosis of granulomatosis with polyangiitis was retained. Treatment with glucocorticoids and immunosuppressive agents resulted in significant clinical and radiological improvement over the following months.
\end{abstract}

Conclusions: We describe the diagnostic steps and the difficulty of managing this patient. Rare manifestations, such as retroperitoneal fibrosis, have been reported in the literature in association with granulomatosis with polyangiitis, and should not delay the diagnosis and treatment of granulomatosis with polyangiitis owing to its severity.

Keywords: Granulomatosis with polyangiitis, Retroperitoneal fibrosis, Venous thromboembolism, Cytoplasmic antineutrophilic antibodies

\section{Introduction}

Granulomatosis with polyangiitis (GPA) is a necrotizing vasculitis affecting predominantly small to medium vessels (capillaries, venules, arterioles, arteries, and veins) [1]. This condition was previously known as Wegener's granulomatosis. It is a rare disease, with an incidence in Europe of 2.1-14.4 cases/million, and it occurs in all age groups [2]. An increased incidence of various vascular events was demonstrated among GPA patients. We have shown that GPA patients are at increased risk

\footnotetext{
*Correspondence: Dr.hanane.charaf@gmail.com

${ }^{1}$ Pneumo-Phtisiology Department, Faculty of Medicine and Pharmacy, Mohamed V University, Moulay Youssef Hospital, Rabat, Morocco

Full list of author information is available at the end of the article
}

of hospitalization for ischemic heart disease manifestations compared with age- and sex-matched controls [3]. For venous thromboembolic events (VTE), Merkel et al. reported a high occurrence of pulmonary embolism (PE) and deep venous thrombosis (DVT) among GPA patients included in a randomized therapeutic trial [4]. Among the observed VTEs, $81 \%$ occurred in patients with active or recently active vasculitis. Alvise Berti et al. found that, for patients with cytoplasmic antineutrophilic antibodies (ANCA)-associated vasculitis (AAV), the hazard ratio (HR) for venous thromboembolism VTE was 3.26 [95\% confidence interval (CI) 0.84-12.60] and significantly increased for peripheral vascular disease DVT (HR 6.25, 95\% CI 1.16-33.60), but not for pulmonary embolism (PE; HR 1.33, 95\% CI 0.23-7.54) [5]. Other structures original author(s) and the source, provide a link to the Creative Commons licence, and indicate if changes were made. The images or other third party material in this article are included in the article's Creative Commons licence, unless indicated otherwise in a credit line to the material. If material is not included in the article's Creative Commons licence and your intended use is not permitted by statutory regulation or exceeds the permitted use, you will need to obtain permission directly from the copyright holder. To view a copy of this licence, visit http://creativecommons.org/licenses/by/4.0/. The Creative Commons Public Domain Dedication waiver (http://creativeco mmons.org/publicdomain/zero/1.0/) applies to the data made available in this article, unless otherwise stated in a credit line to the data. 
such as the retroperitoneal tissue, or large vessels including the aorta, are rarely involved. Retroperitoneal fibrosis incidence is 0.1 per 100,000 population/year with a prevalence of 1.4 per 100,000 population. Seventy percent of cases are idiopathic [2].

We present a case of multiple vascular thromboses, revealing granulomatous polyangiitis associated with retroperitoneal fibrosis without periaortitis. The association of retroperitoneal fibrosis with c-ANCA or p-ANCA positive systemic vasculitis is described in the literature, not only for granulomatosis with polyangiitis but also in other vasculitides such as Churg-Strauss syndrome [2].

The diagnosis of this association is lengthy and costly, with a lot of exploration [positron emission tomography (PET) scan and anatomopathological analysis of biopsies], which causes a delay in diagnosis that can expose the patient to complication risk $[2,3,5]$.

Our observation describes the diagnostic particularity and management of this association, and we insist that retroperitoneal fibrosis should not delay the diagnosis of GPA or defer its therapeutic management.

\section{Case description}

The 66-year-old Moroccan male patient had a cumulative smoking index of 30 pack-years. The patient stopped smoking 5 years earlier, had no alcoholism, and had no personal or family history or professional or environmental exposure for bilateral jugular thrombosis. He was put on antivitamin $\mathrm{K}$ for 1 month and still developed thoracic pains with productive coughing bringing up hemoptoic sputum, lumbago, dysphonia, epistaxis, and deafness of the left ear of acute installation. At admission, the patient was respiratorily and hemodynamically stable. The general examination on admission revealed a conscious patient with good orientation in time and space, with a heart rate of 63 beats per minute, blood pressure of $120 / 60 \mathrm{~mm} \mathrm{Hg}$, respiratory rate of 16 breaths per minute, and temperature of $37^{\circ} \mathrm{C}$. On neurological examination, mobility, sensitivity, and osteotendinous reflexes were preserved. Examination of the cranial nerves was without anomalies. The rest of the physical examination was unremarkable except for red eyes and some leg purpuric lesions (Table 1). There were no peripheral signs of heart failure and no signs of peritoneal irritation on percussion, and chest X-ray showed several excavated opacities (Fig. 1). The thoracoabdominopelvic computed tomography scan revealed multiple thromboses, particularly in the jugular veins (Fig. 2), extended to the brachiocephalic trunk and the superior vena cava, and in the left common femoral vein, a left intraventricular thrombus. The sinus scan revealed chronic maxillary sinusitis with episcleritis perforation of its medial wall (Fig. 3), excavated bilateral nodular pulmonary lesions (Fig. 4) associated with a periaortic adenopathy flow, and a fly sheathing the aorta suggestive of retroperitoneal fibrosis (Fig. 5). The routine blood and urine analysis detected anemia. Renal and hepatic function were normal, and hepatitis $B$ and $C$ and human immunodeficiency virus (HIV) serologies were negative. There was an increase of the acute phase reactant C-reactive protein (CRP) $188 \mathrm{mg} / \mathrm{L}$ (normal value $\leq 6 \mathrm{mg} / \mathrm{L}$ ), an increase of 24 -hour proteinuria to $1.4 \mathrm{~g} / \mathrm{L}$ (normal value $0.3 \mathrm{~g} / \mathrm{L}$ ), microscopic hematuria detected on cytobacteriological examination of urine, urinary sediment positive for blood and albumin, acid-alcohol resistant bacillus in sputum negative with GeneXpert analysis, antiphospholipid antibodies negative, and anticytoplasmic antibodies of neutrophilic

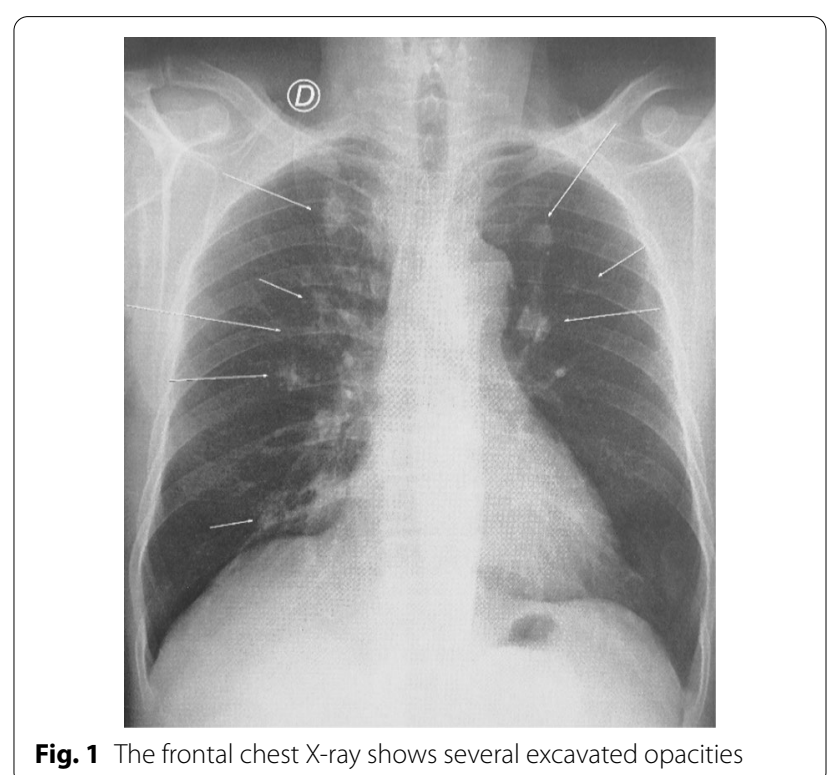

Table 1 The chronology of clinical signs

\begin{tabular}{ll}
\hline Time & Clinical presentation \\
\hline T0 & Bilateral jugular thrombosis \\
T1 1 month & Chest pain with productive cough bringing up hemoptoid sputum \\
T2 1 month and 1 week & Lumbago, dysphonia, epistaxis, deafness of the left ear \\
T3 1 month and 10 days & Red eyes and some purpuric lesions on the legs \\
\hline
\end{tabular}




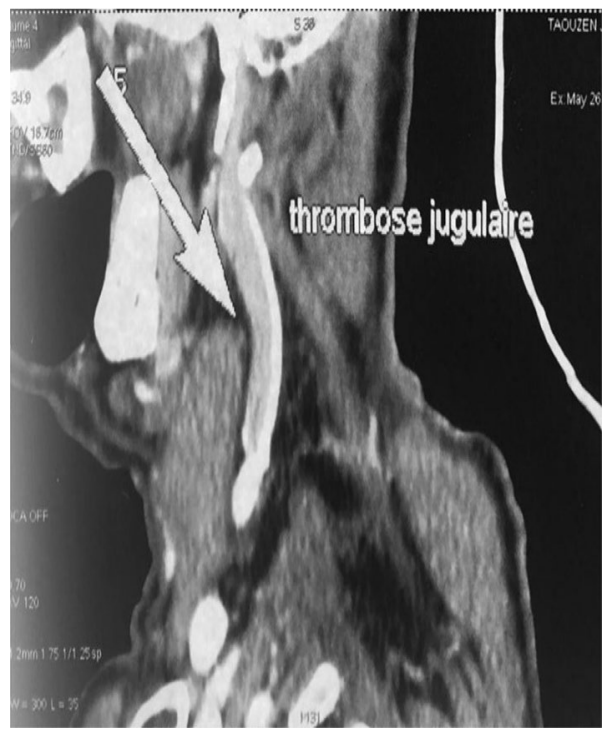

Fig. 2 Partial thrombosis of the jugular vein

polynuclear antibodies ANCA-PR3 positive to $63 \mathrm{UI} /$ $\mathrm{mL}$. Ear, nose, and throat examination showed a highly inflamed nasal mucosa, suggesting bacterial infection. The patient received antibiotic treatment, the examination also showed subglottic stenosis causing dysphonia. Ophthalmologic examination was indicative of bilateral episcleritis. Transthoracic ultrasound showed ischemic cardiomyopathy, which was complicated by a left intraventricular thrombus and a circumferential effusion with fibrin deposits. Other complementary tests, such as PET scan or biopsy (pulmonary, nasal, renal, retroperitoneal fibrosis), did not lead to suspicion of neoplastic pathology or therapeutic urgency. Based on these results, we diagnosed GPA with cardiovascular, pulmonary, renal, and nasal involvement associated with retroperitoneal fibrosis (Tables 2,3). In addition to the anticoagulant [warfarin $2 \mathrm{mg}$ with international normalized ratio (INR) of 2], the patient was treated with immunosuppressive therapy [bolus of methylprednisolone $15 \mathrm{mg} / \mathrm{kg} /$ day 3 days in a row, bolus of cyclophosphamide Endoxan $500 \mathrm{mg} / \mathrm{m}^{2}$ with Uromitexan (mesna) $500 \mathrm{mg} / \mathrm{m}^{2}$ ), and oral corticosteroids $(1 \mathrm{~m} / \mathrm{kg})$ ], (Tables 4,5$)$, with clinical improvement including the disappearance of dyspnea and hemoptysis, radiological improvement including regression of excavated nodules (Fig. 6), decrease in the size of the periaortic infiltrate (Fig. 7), and a slight improvement in renal function (24-hour proteinuria of control at $0.7 \mathrm{mg} / \mathrm{L}$ ) and ANCA levels (ANCA of control at $53 \mathrm{UI} / \mathrm{mL}$ ) (Table 4). The follow-up was complicated by several relapses, hospitalization, and an increase of corticosteroid therapy

\section{Discussion}

Granulomatosis with polyangiitis (Wegener's) is a necrotizing vasculitis combining inflammation of the vascular wall with peri- and extravascular granulomatosis [2]. Despite the discovery of anti-PR3 ANCAs that are highly specific for GPA, the pathogenesis of this disease is still poorly understood; however, neutrophils are the key players because they produce the autoantigen, proteinase 3 , and their regulation is altered in patients [2]. Clinically, it is characterized in its full form by ENT signs and lung and kidney involvement. Other systemic manifestations may occur, and the risk of VTE is high [7]. Chest X-rays
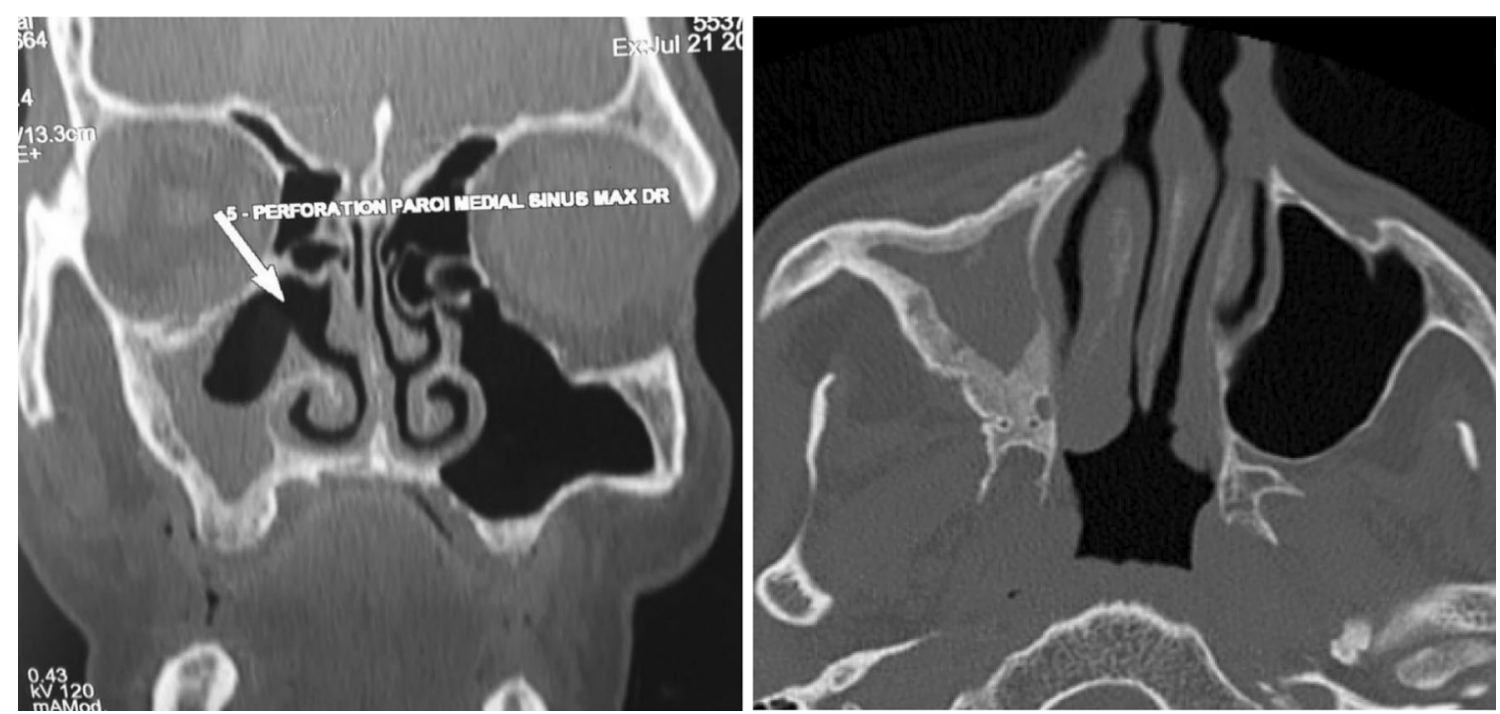

Fig. 3 Sinus CT scan, axial section, frontal section: filling of the right maxillary sinus (sinusitis) with an erosion of the bone wall 


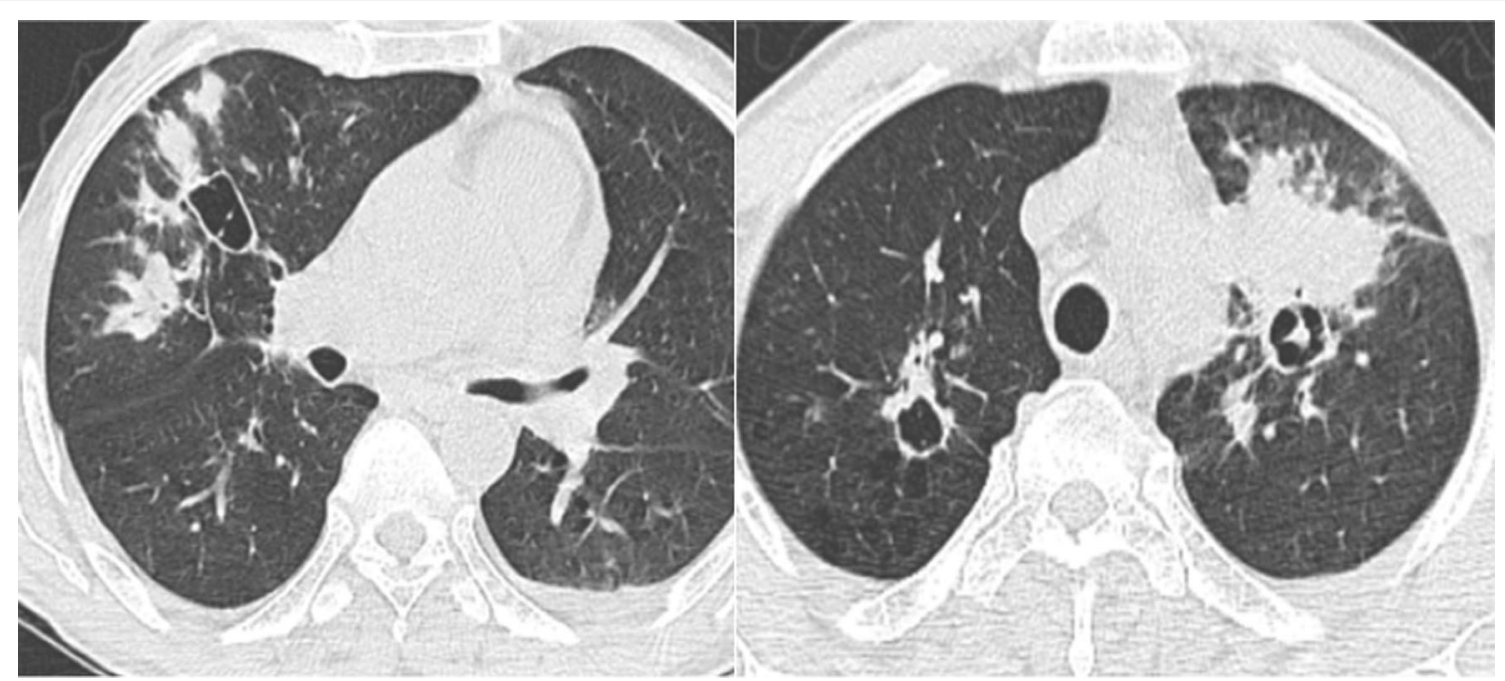

Fig. 4 Thoracic CT scan, parenchymal window, axial sections: multiple excavated intraparenchymal lung nodules, irregularly contoured, thick-walled

and CT scans show nodules, single or bilateral, single or multiple, excavated in half of the cases. Single or bilateral pulmonary infiltrates may also appear. Granulomatous pseudotumoral lung masses are possible $[2,6]$ (Table 1).

The presence of thrombosis in GPA is frequent. Analysis of a randomized controlled trial Wegener's Granulomatosis Etanercept Trial (WGET), which included patients with GPA, showed a VTE incidence of 7.0 per 100 person-years [4]. An increased likelihood of VTE was reported in a population-based incident AAV cohort, which was driven by a significantly increased risk of developing deep venous thrombosis (DVT) [7]. The analysis of a large cohort of patients with eosinophilic granulomatosis with polyangiitis (EGPA), GPA, and MPA demonstrated occurrence of VTEs in $8.2 \%, 8.0 \%$, and $7.8 \%$ of patients, respectively [8]. In a prospective study, Merkel et al. [4] found an increased incidence of 7.0/100 person-years of VTE in Wegener granulomatosis (WG) patients. For comparison, in healthy Swedish men, the incidence is $0.3 / 100$ person-years [9]. The cause of this increased incidence of VTE in WG patients cannot be derived from the study of Merkel et al. More recently, an analysis of data derived from several trials conducted by the European Vasculitis Society showed VTE occurrence in 41 (9.8\%) of 417 patients with GPA or MPA [10]. Hansson et al. found an increased incidence of VTE just before and after the diagnosis of AAV of 1.8/100 personyears, compared with 0.3 in a healthy population of the same age [9]. The cause of the increased risk of VTE in AAV patients, especially when the disease is active, is unknown. Changes in endothelial function and hypercoagulability, especially during active disease, could explain this risk of VTE. Both cytokines and ischemia are known to cause endothelial damage [11]. Circulating ANCAs may also cause endothelial damage [12]. Increased platelet aggregation [11] and decreased fibrinolytic capacity [13] during active disease also appeared to cause thrombosis in AAV patients.

Retroperitoneal fibrosis (RPF) is very rare in granulomatosis with polyangiitis. The incidence of RPF is 0.1 per 100,000 population/year, with a prevalence of 1.4 per 100,000 population. Seventy percent of cases are idiopathic [14]. The remaining cases may be secondary to infections, abdominal surgery, medication, or malignant tumors. Recently, idiopathic retroperitoneal fibrosis was reported among the manifestations of immunoglobulin (Ig)G4 disease. This disease is responsible for only a portion of idiopathic retroperitoneal fibrosis cases (50\%) $[15,16]$. Imaging plays an important role in the diagnosis of RPF, in the distinction between benign and malignant forms, and finally in the monitoring of the evolution under treatment [14]. However, if diagnostic dilemmas exist and an underlying malignancy is suspected, or if there is no response to initial treatment, biopsy must be performed to confirm the diagnosis.

The association of retroperitoneal fibrosis with c-ANCA or p-ANCA positive systemic vasculitis is described in the literature, for granulomatosis with polyangiitis as well as in other vasculitides such as ChurgStrauss syndrome [17]. Revilla et al. reported a case of a 74-year-old man with a past infrarenal abdominal aortic aneurysm. Cavitating pulmonary nodules and retroperitoneal fibrosis with periaortic alterations were detected on computed tomography. Laboratory investigations 

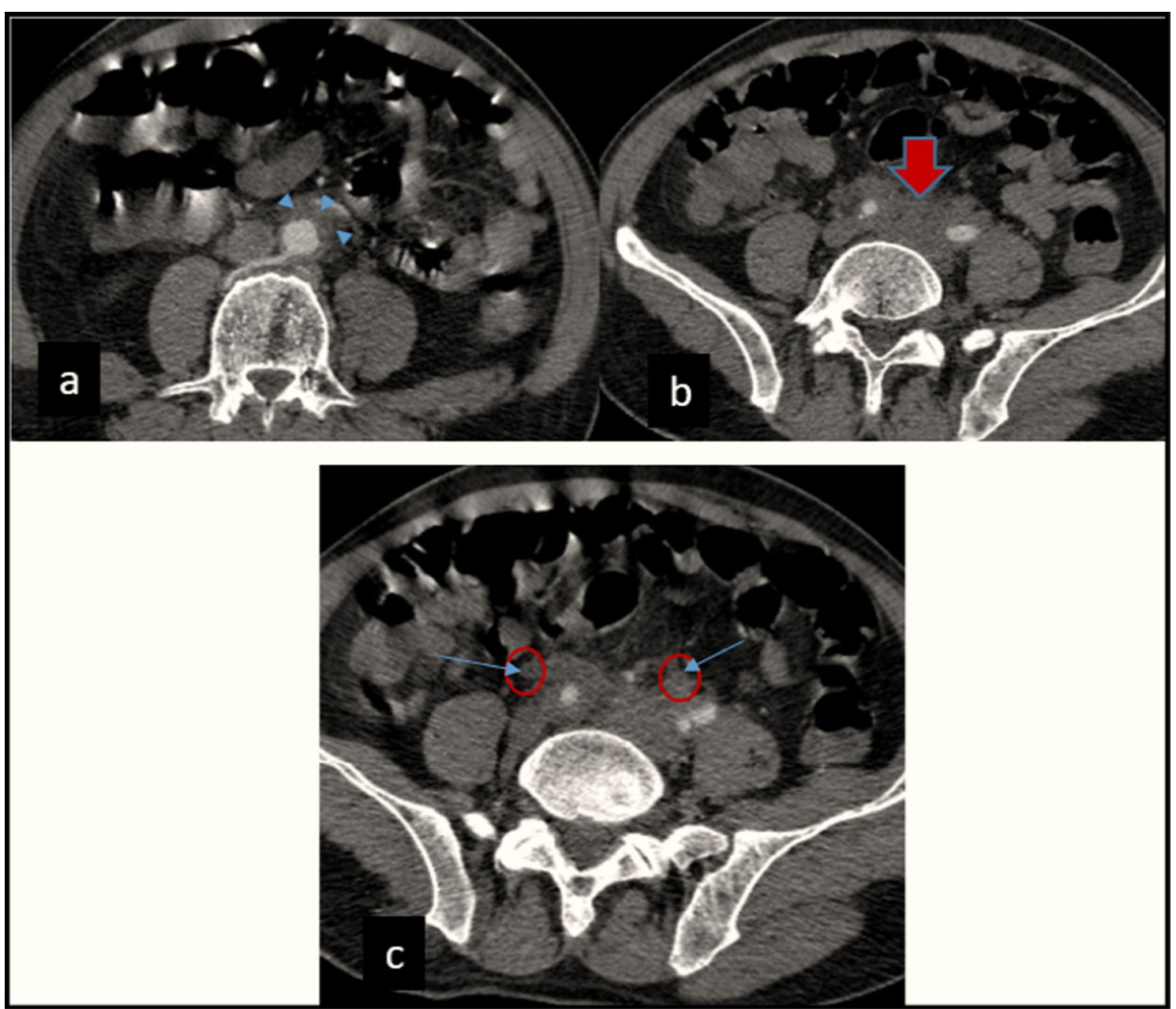

Fig. 5 Abdominal CT scan, axial section:; tissue density infiltrate (or sleeve), homogeneous, perivascular, sheathing the abdominal aorta (a arrowheads), extending to the iliac arteries (b, red arrow) and iliac ureters (c, blue arrows) in favor of retroperitoneal fibrosis (RFP)

Table 2 The diagnostic criteria in our patient

\begin{tabular}{ll}
\hline Diagnostic criteria & Arguments \\
\hline Clinical & Lung: chest pain with hemoptoic sputum, bilateral nodular excavated lung lesions \\
& Kidney: microscopic hematuria, positive urine sediment, 24-hour proteinuria \\
& ENT: dysphonia, epistaxis, left ear deafness, subglottic stenosis on nasofibroscopy, perforation of the medial sinus wall \\
& Ophthalmic: red eyes, bilateral episcleritis \\
& Cardiovascular involvement: multiple thrombosis, circumferential pericardial effusion \\
& Lumbar: lumbago, retroperitoneal fibrosis \\
Biology & Anticytoplasmic neutrophil antibodies ANCA-PR3 positive at $63 \mathrm{IU} / \mathrm{mL}$ \\
Histology & Biopsies not done because of the therapeutic emergency and the impossibility of stopping the anticoagulant treatment
\end{tabular}

ENT: Eyes, Nose, Throat; ANCA-PR3: anti-neutrophil cytoplasmic antibodies proteinase 3

revealed that the patient was positive for cytoplasmic antineutrophil cytoplasmic antibodies (c-ANCA), and necrotizing granulomas were observed on the lung lesion biopsies retroperitoneal tissue. The patient was diagnosed with GPA, and immunosuppressive therapy was prescribed with glucocorticoids $1 \mathrm{mg} / \mathrm{kg}$ for 3 days and methotrexate $20 \mathrm{mg}$ per week, which led to a clinical and radiological improvement [2]. Izzedine et al. reported the case of a 51-year-old man with abdominal pain, urinary symptoms, and a constitutional 
Table 3 Diagnostic criteria

\begin{tabular}{l}
$\begin{array}{l}\text { Diagnostic criteria granulomatosis with polyangiitis: should show } \\
\text { two or more criteria }\end{array}$ \\
\hline Nasal or oral inflammation \\
Abnormal thoracic X-ray \\
Active urinary sediment \\
Granulomatous inflammation in the biopsy \\
\hline
\end{tabular}

syndrome. Imaging revealed retroperitoneal fibrosis. Necrotizing granulomas, giant cells, and a lympho-epithelioid cellular infiltrate were observed on the retroperitoneal tissue biopsy. The patient responded poorly to antituberculous treatment. Finally, a renal biopsy was performed, which revealed pauci-immune rapidly progressive glomerulonephritis with necrotizing vasculitis. Alveolar opacities compatible with alveolar hemorrhages were observed on thoracic $\mathrm{CT}$, and a diagnosis of GPA was made. The patient showed significant improvement after treatment with immunosuppressive agents and corticosteroids [18].

These observations show that, if the clinical presentation is suggestive of vasculitis, the discovery of retroperitoneal fibrosis should not lead to further investigations and will be considered secondary to GPA. Immunosuppressive treatment must be started quickly given the rapid evolution of the disease and the functional and vital prognosis involved. Our observation confirms this notion. The diagnosis of RPF has been attributed to GPA; in this sense, the complementary examinations (PET scan and biopsy) in search of neoplasia or other etiology have not been realized. Our patient responded favorably to immunosuppressive therapy and corticosteroids. The similarly responding retroperitoneal lesion may suggest that this is an unusual presentation in GPA.

\section{Conclusion}

Granulomatosis with polyangiitis is a systemic, multiorgan disease with an increased risk of VTE; however, the association with retroperitoneal fibrosis remains rare,

Table 4 Clinical course and follow-up visits

\begin{tabular}{lll}
\hline Time & Treatment administered & Clinical, biological, and radiological evolution \\
\hline T0 & A bolus of methylprednisolone 3 days in a row & Disappearance of purpuric lesions \\
T1 day 4 & A first bolus of Endoxan $+60 \mathrm{mg}$ prednisone & $\begin{array}{l}\text { Disappearance of chest pain } \\
\text { Cessation of hemoptysis and epistaxis } \\
\text { T2 } 2 \text { weeks }\end{array}$ \\
T3 2 weeks & Second bolus of Endoxan $+60 \mathrm{mg}$ prednisone & Regression of pulmonary nodules and periaortic infiltration \\
T4 3 weeks & 3rd bolus of Endoxan $+60 \mathrm{mg}$ prednisone & Decrease in cANCA \\
T5 3 weeks & Fourth bolus of Endoxan $+60 \mathrm{mg}$ prednisone & Decrease in 24-hour proteinuria \\
T6 3 weeks & Fifth bolus of Endoxan $+40 \mathrm{mg}$ prednisone & Regression of jugular thrombosis \\
T7 1 week from the end of & Azathioprine 50 mg $+30 \mathrm{mg}$ prednisone & Clinical, biological, radiological stability \\
sixth bolus & & Relapse leading to increase in corticotherapy
\end{tabular}

Table 5 Bolus of Endoxan and monitoring

\begin{tabular}{|c|c|c|c|c|c|c|c|c|c|}
\hline \multicolumn{2}{|c|}{$\begin{array}{l}\text { Hour } \mathbf{0} \\
500 \text { saline serum (SS 0.9\%) }\end{array}$} & \multicolumn{2}{|c|}{ Hour 1} & \multirow{2}{*}{$\begin{array}{l}\text { Hour } 2 \\
500 \text { cc of SS } 0.9 \%\end{array}$} & \multirow{2}{*}{$\begin{array}{l}\text { Hour } 3 \\
\text { Furosemide } \\
40 \text { mg intravenous }\end{array}$} & \multicolumn{2}{|l|}{ Hour 4} & \multicolumn{2}{|c|}{ Hour 5} \\
\hline 500 saline serum & $5 S 0.9 \%)$ & \multicolumn{2}{|c|}{$\begin{array}{l}\text { Endoxan } 1 \mathrm{~g} / 500 \text { cc of } \\
\text { glycolic serum (GS 5\%) } \\
1 / 3 \text { solution mesna } \\
(600 \mathrm{mg} / 100 \text { cc GS 5\%) }\end{array}$} & & & \multicolumn{2}{|c|}{$\begin{array}{l}\text { 1/3 solution mesna } \\
\text { ( } 600 \text { mg/100 cc GS 5\%) } \\
\text { Drinking water }\end{array}$} & \multicolumn{2}{|c|}{$\begin{array}{l}\text { 1/3 solution mesna } \\
\text { ( } 600 \text { mg/100 cc GS 5\%) } \\
\text { Drinking water }\end{array}$} \\
\hline Monitoring & Hour 0 & & Hour 1 & Hour 2 & Hour 3 & Hour 5 & Hour 6 & & Hour 7 \\
\hline Blood pressure & \multicolumn{2}{|c|}{ 120/60 mmHg } & $120 / 60 \mathrm{mmHg}$ & 130/70 mmHg & 130/70 mmHg & 120/60 mmHg & \multicolumn{2}{|c|}{$120 / 60 \mathrm{mmHg}$} & $120 / 60 \mathrm{mmHg}$ \\
\hline $\begin{array}{l}\text { Respiratory } \\
\text { frequency }\end{array}$ & \multicolumn{2}{|c|}{$\begin{array}{l}16 \text { breaths per } \\
\text { minute }\end{array}$} & $\begin{array}{l}16 \text { breaths per } \\
\text { minute }\end{array}$ & $\begin{array}{l}17 \text { breaths per } \\
\text { minute }\end{array}$ & $\begin{array}{l}16 \text { breaths per } \\
\text { minute }\end{array}$ & $\begin{array}{l}16 \text { breaths per } \\
\text { minute }\end{array}$ & \multicolumn{2}{|c|}{$\begin{array}{l}16 \text { breaths per } \\
\text { minute }\end{array}$} & $\begin{array}{l}16 \text { breaths per } \\
\text { minute }\end{array}$ \\
\hline Pulse & \multicolumn{2}{|c|}{$\begin{array}{l}63 \text { beats per } \\
\text { minute }\end{array}$} & $\begin{array}{l}70 \text { beats per } \\
\text { minute }\end{array}$ & $\begin{array}{l}73 \text { beats per } \\
\text { minute }\end{array}$ & $\begin{array}{l}75 \text { beats per } \\
\text { minute }\end{array}$ & $\begin{array}{l}70 \text { beats per } \\
\text { minute }\end{array}$ & \multicolumn{2}{|c|}{$\begin{array}{l}65 \text { beats per } \\
\text { minute }\end{array}$} & $\begin{array}{l}65 \text { beats per } \\
\text { minute }\end{array}$ \\
\hline Temperature & \multicolumn{2}{|l|}{$37^{\circ} \mathrm{C}$} & $37^{\circ} \mathrm{C}$ & $37^{\circ} \mathrm{C}$ & $37^{\circ} \mathrm{C}$ & $37^{\circ} \mathrm{C}$ & $37^{\circ} \mathrm{C}$ & & $37^{\circ} \mathrm{C}$ \\
\hline
\end{tabular}




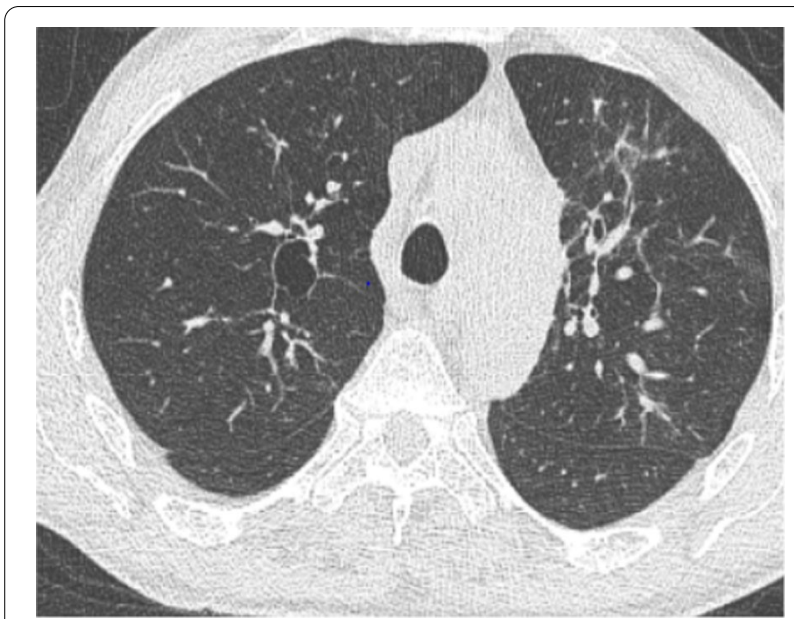

Fig. 6 Thoracic CT scan (performed after the second bolus of cyclophosphamide) showed radiological improvement of excavated nodules with the disappearance of condensation

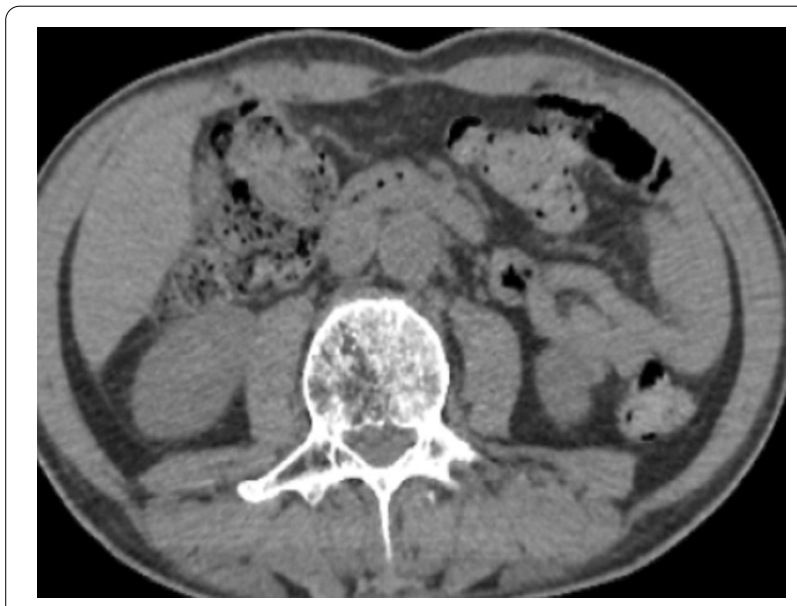

Fig. 7 Spontaneous contrast abdominal CT scan (performed after the second bolus of cyclophosphamide) shows clear regression of periaortic tissue infiltrate

and systematic biopsy does not seem justified in the absence of clinical and/or paraclinical guidance.

\begin{abstract}
Abbreviations
GPA: Granulomatosis with polyangiitis; ENT: Ears, nose, throat; VTE: Venous thromboembolism; c-ANCA: Cytoplasmic antineutrophilic antibodies; PE: Pulmonary embolism; DVT: Deep venous thrombosis; AAV: Cytoplasmic antineutrophilic antibodies-associated vasculitis; HR: Hazard ratio; Cl: Confidence interval; CRP: C-reactive protein; WGET: Wegener's granulomatosis etanercept trial; EGPA: Eosinophilic granulomatosis with polyangiitis; MPA: Microscopic polyangiitis; WG: Wegener granulomatosis; RPF: Retroperitoneal fibrosis; CTscan: Computed tomography scan.
\end{abstract}

\section{Acknowledgments}

Not applicable.

\section{Authors' contributions}

RZ: analyzed and interpreted the patient data and corrected the work in totality. NR: contributed to scientific research. MS: gave the second reading. JEB: gave the second reading. DAM: provided us with the images. IN: provided us with the images. All authors read and approved the final manuscript.

\section{Funding}

This study was supported by biomedcentral (grant no. 6381688120375643), Hanane Charaf.

\section{Availability of data and materials \\ Not applicable.}

\section{Declarations}

\section{Ethics approval and consent to participate}

Not applicable.

\section{Consent for publication}

Written informed consent was obtained from the patient for publication of this case report and any accompanying images. A copy of the written consent is available for review by the Editor-in-Chief of this journal.

\section{Competing interests}

The authors declare that they have no competing interests.

\section{Author details}

${ }^{1}$ Pneumo-Phtisiology Department, Faculty of Medicine and Pharmacy, Mohamed V University, Moulay Youssef Hospital, Rabat, Morocco. ${ }^{2}$ Radiology Department, Faculty of Medicine and Pharmacy, Mohamed V University, Ibn Sina Hospital, Rabat, Morocco.

Received: 4 December 2020 Accepted: 20 December 2021

Published online: 26 January 2022

\section{References}

1. Jennette JC, Falk RJ, Bacon PA, Basu N, Cid MC, et al. Revised International Chapel Hill Consensus Conference Nomenclature of Vasculitides. Arthritis Rheum. 2012;65(1):1-11.

2. Revilla EMG, Fernandez AA, Ramirez MTR, Pardo SC, Moragues MAJ. Retroperitoneal fibrosis with periaortitis: a case report of an unusual form of presentation of granulomatosis with polyangiitis. Respir Med Case Rep. 2016; 121-4

3. Faurschou M, Mellemkjaer L, Sorensen IJ, Thomsen BS, Dreyer L, Baslund B. Increased morbidity from ischemic heart disease in patients with Wegener's granulomatosis. Arthritis Rheum. 2009;60:1187-92.

4. Merkel PA, Lo GH, Holbrook JT, Tibbs AK, Allen NB, Davis JC Jr, et al. Brief communication: high incidence of venous thrombotic events among patients with Wegener granulomatosis: the Wegener's Clinical Occurrence of Thrombosis (WeCLOT) Study. Ann Intern Med. 2005;142:620-6.

5. Berti A. Risk of cardiovascular disease and venous thromboembolism among patients with incident ANCA-associated vasculitis: a 20 year population-based cohort study. Mayo Clin Proc. 2018;93(5):597-606.

6. Gibelin A, Maldini C, Mahr A. Epidemiology and etiology of Wegener granulomatosis, microscopic polyangiitis, Churg-Strauss syndrome, and Goodpasture syndrome: vasculitides with frequent lung involvement. Semin Respir Crit Care Med. 2011;32:264-73.

7. Berti A, Matteson EL, Crowson CS, Specks U, Cornec D. Risk of cardiovascular disease and venous thromboembolism among patients with incident ANCA-associated vasculitis: a 20-year population-based cohort study. Mayo Clin Proc. 2018;93:597-606.

8. Allenbach Y, Seror R, Pagnoux C, et al. High frequency of venous thromboembolic events in Churg-Strauss syndrome, Wegener's granulomatosis and microscopic polyangiitis but not polyarteritis nodosa: a systematic retrospective study on 1130 patients. Ann Rheum Dis. 2009;68:564-7.

9. Hansson PO, Welin L, Tibblin G, Eriksson H. Deep vein thrombosis and pulmonary embolism in the general population. 'The Study of Men Born in 1913.' Arch Intern Med. 1997;157:1665-70. 
10. Kronbichler A, Leierer J, Leierer G, Mayer G, Casian A, Höglund P, et al. Clinical associations with venous thromboembolism in anti-neutrophil cytoplasm antibody-associated vasculitides. Rheumatology (Oxford). 2017:56:704-8.

11. Somer T. Thrombo-embolic and vascular complications in vasculitis syndromes. Eur Heart J. 1993;14:24-9.

12. Jennette JC, Xiao H, Falk RJ. Pathogenesis of vascular inflammation by antineutrophil cytoplasmic antibodies. J Am Soc Nephrol. 2006;17:1235-42.

13. Jordan JM, Allen NB, Pizzo SV. Defective release of tissue plasminogen activator in systemic and cutaneous vasculitis. Am J Med. 1987;82:397-400.

14. Langford CA, Talar-Williams C, Sneller MC. Use of methotrexate and glucocorticoids in the treatment of Wegener's granulomatosis. The longterm renal outcome in patients with glomerulonephritis. Arthritis Rheum. 2001;43:8.

15. Zen Y, Onodera M, Inoue D, et al. Retroperitoneal fibrosis: a clinicopathologic study with respect to immunoglobulin G4. Am J Surg Pathol. 2009;33:1833-9.

16. Koo BS, Koh YW, Hong S, et al. Clinicopathologic characteristics of IgG4related retroperitoneal fibrosis among patients initially diagnosed as having idiopathic retroperitoneal fibrosis. Mod Rheumatol. 2015;25:194-8.

17. Fujii K, Hidaka Y. Churg-strauss syndrome complicated by chronic periaortitis: a case report and review of the literature. Intern Med. 2012;51:109-12.

18. Izzedine H, Servais A, Launay-Vacher V, Deray G. Retroperitoneal fibrosis due to Wegener's granulomatosis: a misdiagnosis as tuberculosis. Am J Med. 2002;113:164-6.

\section{Publisher's Note}

Springer Nature remains neutral with regard to jurisdictional claims in published maps and institutional affiliations.

- fast, convenient online submission

- thorough peer review by experienced researchers in your field

- rapid publication on acceptance

- support for research data, including large and complex data types

- gold Open Access which fosters wider collaboration and increased citations

- maximum visibility for your research: over 100M website views per year

At BMC, research is always in progress.

Learn more biomedcentral.com/submissions 